\title{
Sobreviventes do transplante de medula óssea: construção do cotidiano*
}

\section{Bone marrow transplantation survivors: reconstruction of daily living}

\author{
Ana Paula Mastropietro ${ }^{1}$, Manoel Antônio dos Santos², \\ Érika Arantes de Oliveira ${ }^{3}$
}

MASTROPIETRO, A. P.; SANTOS, M. A.; OLIVEIRA, E. A. Sobreviventes do transplante de medula óssea: construção do cotidiano. Rev. Ter. Ocup. Univ. São Paulo, v. 17, n. 2, p. 64-71, maio/ago., 2006.

\begin{abstract}
RESUMO: O Transplante de Medula Óssea (TMO) é um procedimento de alta complexidade cujo desenvolvimento, nas últimas décadas, permitiu o tratamento de doenças que antes eram invariavelmente fatais. O transplante é constituído por diversas fases estressoras para o paciente, englobando três momentos: pré-TMO, TMO propriamente dito e a fase pós-TMO. Esse último momento é marcado por uma série de restrições aos pacientes, que têm sua rotina de vida totalmente alterada. O objetivo principal do presente estudo é o de avaliar a (re)construção do cotidiano dos pacientes que foram submetidos ao Transplante de Medula Óssea. A amostra foi composta por vinte e quatro pacientes que se encontravam na fase pós-TMO. Para a coleta de dados foi utilizada a Entrevista de Recuperação Pós-TMO (ER-PTMO), instrumento construído para o presente estudo. A entrevista foi gravada e transcrita literalmente e na íntegra. Em sua análise foi utilizada a análise de conteúdo temática. Os resultados indicam que o tempo pós-TMO está diretamente relacionado com a construção do cotidiano dos indivíduos sobreviventes do TMO. Esse fenômeno pode ser atribuído a uma esperada melhora gradual da condição orgânica do paciente e à redução das limitações decorrentes do próprio tratamento (impossibilidade de exercer atividades que envolvam esforços físicos, uso intenso de medicações, retornos ambulatoriais freqüentes, possibilidade de recaída da doença, dentre outras). Os indicadores de readaptação psicossocial no pós-TMO sugerem o êxito do procedimento, que cada vez mais tem se firmado como importante opção terapêutica para diversas enfermidades.
\end{abstract}

DESCRITORES: Terapia ocupacional. Transplante de medula óssea/adaptação psicológica. Transplante de medula óssea/psicologia. Transplante de medula óssea/reabilitação. Apoio social. Reabilitação.

\footnotetext{
* Este trabalho é parte da Dissertação de Mestrado Construção do cotidiano de pacientes submetidos ao transplante de medula óssea: readaptação funcional e reinserção ocupacional, de autoria da primeira autora, sob orientação do segundo autor.

${ }^{1}$ Terapeuta Ocupacional da Unidade de Transplante de Medula Óssea do Hospital das Clínicas da Faculdade de Medicina de Ribeirão Preto da Universidade de São Paulo. Doutoranda pelo Programa de Pós-graduação em Psicologia da Faculdade de Filosofia, Ciências e Letras de Ribeirão Preto da Universidade de São Paulo.

${ }^{2}$ Mestre e Doutor em Psicologia Clínica pelo Instituto de Psicologia da Universidade de São Paulo. Professor Doutor do Curso de Graduação e do Programa de Pós-Graduação em Psicologia da Faculdade de Filosofia, Ciências e Letras de Ribeirão Preto da Universidade de São Paulo. Bolsista de Produtividade de Pesquisa do CNPq.

${ }^{3}$ Psicóloga da Unidade de Transplante de Medula Óssea do Hospital das Clínicas da Faculdade de Medicina de Ribeirão Preto da Universidade de São Paulo. Doutora pelo Programa de Pós-graduação em Psicologia da Faculdade de Filosofia, Ciências e Letras de Ribeirão Preto da Universidade de São Paulo.

Endereço para correspondência: Anel Viário Contorno Sul Km 319, Condomínio Garden Villa, 314, Casa 13c, CEP: 14031 -800 - Ribeirão Preto - SP. e-mail: anapmastro@bol.com.br
} 


\section{TRANSPLANTEDEMEDULAÓSSEA}

A tualmente o Transplante de Medula Óssea TMO) vem se constituindo como uma alternativa de tratamento para diversos tipos de neoplasias, doenças hematológicas ou não, doenças metabólicas e deficiências imunológicas. Compondo o quadro de diagnósticos que recebem indicações para o TMO tem-se, dentre outros: Leucemia Mielóide Crônica, Leucemia Mielóide Aguda, Leucemia Linfóide Aguda e as "préleucemias" (mielodisplasias), Doença de Hodgkin e Linfoma Não-Hodgkin, tumores sólidos, bem como as desordens adquiridas: aplasia da medula, síndrome mielodisplásica, desordens imunológicas, talassemias, anemia de Fanconi e anemia falciforme (VOLTARELLI; STRACIERI, 2000).

Os transplantes atravessam algumas fases comuns, que podem ser caracterizadas em termos de semelhanças e diferenças. Consultando-se a literatura, observa-se que, embora diferentes autores descrevam um número distinto de fases, as diversas descrições incluem os momentos: préTMO (preparação para o transplante); regime de condicionamento; aspiração, processamento e infusão da medula óssea, enxertamento da medula, alta hospitalar e acompanhamento ambulatorial (ANDRYKOWSKI, 1994). Assim, o TMO pode ser visto como ciclos que se sucedem, com ritos de passagem específicos. Para os objetivos do presente estudo, iremos nos deter em dois momentos, aqui denominados de pós-TMO imediato e pós-TMO tardio.

A fase pós-TMO imediato inicia-se com o seguimento em hospital dia, depois da alta do regime de isolamento protetor na enfermaria, quando o paciente prosseguirá o tratamento das diversas complicações decorrentes do transplante e/ou do aparecimento da Doença do Enxerto Contra o Hospedeiro (DECH) agudo. A DECH consiste na proliferação de populações celulares imunologicamente competentes do doador que insurgem contra estruturas antigênicas do receptor imune (PATON et al., 2000). Nesta fase o paciente geralmente fica hospedado na Casa de Apoio conhecida pela sigla GATMO (Grupo de Apoio ao Transplantado de Medula Óssea) e vem todos os dias ao hospital, que oferece abrigo e alimentação apropriada. Caso seja proveniente de Ribeirão Preto, SP, o paciente é liberado para voltar ao convívio familiar e passa a vir ao hospital em retornos diários.

Nessa fase do tratamento, o paciente está vivenciando uma série de restrições do TMO, tais como: só se alimentar com alimentos cozidos, beber no mínimo três litros de água fervida por dia, ingerir no mínimo 257 comprimidos por dia, usar máscara em virtude da sua condição de imunossuprimido, não permanecer em ambiente com condições de higiene precária, evitar o contato com aglomeração de pessoas ou com pessoas que possam estar gripadas ou com qualquer outro quadro viral ou infeccioso, não se aproximar de animais domésticos, manter-se distante de crianças que acabaram de tomar vacinas, não ter relacionamento sexual, passear ao ar livre apenas em períodos pré-estipulados pela equipe, não utilizar transporte coletivo, praticar atividades esportivas somente com orientação médica, evitar exposição ao sol (VOLTARELLI; STRACIERI, 2000). Essa etapa cessa ao completar 100 dias do enxertamento da medula, desde que as complicações decorrentes do tratamento estejam controladas.

No pós-TMO tardio aparecem as complicações tardias, como a Doença do Enxerto versus Hospedeiro em sua forma crônica-DECH crônica e, ainda, problemas de esterilidade, catarata e recaída da doença de base (PATON et al., 2000). Esse momento é marcado pela alta do paciente do hospital dia e o início do seguimento no ambulatório. Para os pacientes recém-chegados ao ambulatório os retornos são mensais, evoluindo para retornos a cada seis meses, até atingir retornos anuais (VOLTARELLI; STRACIERI, 2000). Assim, paulatinamente, a proteção do ambiente hospitalar é trocada pelo ambiente doméstico, marcando o fim da plena dependência em prol da progressiva autonomia.

A maioria dos pacientes que se encontram nessa fase já retornou para casa e está tentando retomar suas atividades cotidianas. No início necessitam tomar maior cuidado com as diversas restrições impostas pelo TMO. Com a melhora gradual da condição orgânica do paciente e o restabelecimento do sistema autoimune, que permite a suspensão das drogas imunossupressoras, paulatinamente vai ocorrendo uma redução das limitações decorrentes do próprio tratamento, que vão sendo sucessivamente superadas.

Nas fases posteriores ao TMO uma das preocupações mais recorrentes, tanto dos profissionais quanto do paciente e familiares, diz respeito a como vai ser a reestruturação do cotidiano do paciente submetido ao TMO quando estiver fora do hospital.

\section{CONSIDERAÇÕES SOBRE O CONCEITO DE COTIDIANO, RELEVANTES PARA A TERAPIA OCUPACIONAL}

O conceito de cotidiano surge no século XVIII com o advento do capitalismo, quando ocorre uma separação radical entre a casa e a fábrica. A partir daí criam-se vários cotidianos, que lidam com tempos e espaços diferenciados: do trabalho, da casa, da rua, do fazer artístico, entre outros (FERRARI et al., 2002). 
A vida cotidiana, sob vários aspectos, passa a ser heterogênea, sobretudo no que se refere ao conteúdo e à significação ou importância que o paciente atribui a cada parte orgânica do cotidiano, tais como: organização do trabalho, vida privada, lazer, descanso, atividades sociais sistematizadas, intercâmbio e purificação (HELLER, 2000).

Segundo Takatori (2001), o cotidiano é entendido na Terapia Ocupacional como a sucessão de acontecimentos vividos, que incluem espaços sociais, tempos diversos, pessoas e objetos variados e que se desenrolam no dia-a-dia.

Para Takatori (2003), a singularidade do sujeito e das características do seu cotidiano é entendida como uma determinada forma de ser e fazer em um determinado ambiente, no qual o sujeito estabelece relações por meio de diversas experiências às quais ele imprime sua marca pessoal. O cotidiano, nessa perspectiva, é considerado como um espaço e um tempo ocupados de forma também singular. Mais do que uma rotina automatizada de horários ou uma seqüencia mecânica de atividades ou procedimentos repetidos como um ritual, o cotidiano é uma forma pessoal de viver a própria história.

Levando-se em consideração a amplitude e a complexidade envolvidas no conceito de construção do cotidiano, que é objeto do presente estudo, e considerandose que ele é necessário para a avaliação não somente de quais são as atividades que preenchem a vida diária dos pacientes, mas também do papel e da satisfação particular auferida por cada sujeito frente a essa construção, optouse por uma abordagem teórico-metodológica qualitativa, com a pretensão de avaliar as diferentes dimensões que podem estar envolvidas, influenciando e sendo influenciadas por esse conceito, como a história clínica e a história de vida atual.

Assim, este estudo tem por objetivo avaliar a construção do cotidiano dos pacientes que foram submetidos ao transplante de medula óssea, assim como caracterizar seu perfil sócio-demográfico e clínico, além de conhecer a situação ocupacional, as expectativas, estratégias de enfrentamento e projetos futuros.

\section{MATERIALEMÉTODO}

\section{Amostra}

A amostra foi composta por 24 pacientes que foram submetidos ao TMO e que ainda estavam em acompanhamento (fase pós-TMO) no Hospital Dia e no Ambulatório da Unidade de TMO do Hospital das Clínicas da Faculdade de Medicina de Ribeirão Preto-USP, no período de julho de 2002 a dezembro de 2002.
Foram estabelecidos os seguintes critérios de inclusão: ter idade superior a 21 anos, apresentar disponibilidade para colaborar voluntariamente com a pesquisa; ter se submetido ao TMO no HCFMRP-USP e estar em acompanhamento, na fase do pós-TMO; ter sido atendido no hospital-dia e ambulatório no período de julho a dezembro de 2002; não ser portador de transtornos psiquiátricos; ter pelo menos três anos de escolaridade formal.

\section{Perfil sócio-demográfico e clínico}

Os 24 pacientes que compuseram a amostra foram subdivididos de forma igualitária em termos do gênero (12 homens e 12 mulheres). A idade variou entre 20 e 59 anos, sendo a idade média de 32,8 anos. A maioria dos pacientes $(n=15)$ era constituída de jovens adultos (21 a 35 anos de idade). O grau de instrução variou de 3 a 15 anos (média de 7,1 anos de escolaridade, $\pm 3,3$ anos), sendo que a maioria dos pacientes (14) tinha até oito anos de escolaridade.

Em relação ao trabalho, 13 encontravam-se inativos no momento da avaliação e 11 ativos, quatro mantinham-se na mesma função exercida anteriormente e sete estavam ocupados em funções diferentes da que mantinham antes de adoecerem. As ocupações referidas pelos pacientes que trabalhavam antes do transplante são condizentes com o baixo nível de escolaridade. Em sua grande maioria, são ocupações que exigem habilidades manuais e um baixo nível de qualificação profissional. As profissões referidas foram: lavrador(a) (sete pacientes), pedreiro (dois pacientes), costureira (duas pacientes), mecânico, metalúrgico, ajudante de serralheiro, moto-taxi, gerente de produção, oficial administrativo, secretária, manicure, balconista e doméstica. Já aqueles pacientes que relataram que não exerciam qualquer ocupação previamente ao TMO, e que continuaram, portanto, fora do mercado formal de trabalho após o transplante, observou-se que se tratavam de donas de casa.

Em relação ao estado civil, a maioria encontrava-se vivendo na companhia do cônjuge por ocasião da coleta de dados $(n=21)$. O diagnóstico médico predominante foi de doença neoplásica $(n=20)$. Quanto às complicações orgânicas pós-TMO, 11 apresentaram algum tipo de problema, sendo: dois pacientes tiveram DECH crônico, dois DECH agudo, três sofreram recidiva da doença de base e dois tiveram pneumonia. Houve ainda um caso de $\mathrm{DECH}$ crônico associado à recaída e um de $\mathrm{DECH}$ agudo e pneumonia.

Em relação ao tempo pós-TMO, 13 haviam sido transplantados havia mais de um ano - variando de sete anos a um ano e cinco meses, ao passo que 11 pacientes 
haviam realizado o transplante há menos de um ano, variando nesses casos de dois a oito meses. Considerandose a totalidade da amostra, a média de tempo decorrido da realização do TMO foi de 28 meses ( $\pm 25,9$ meses).

\section{Instrumento}

$\mathrm{Na}$ tentativa de alcançar os objetivos propostos foi construído um roteiro de entrevista semi-estruturada, denominado Entrevista de Recuperação Pós-TMO (ERPTMO) e realizada uma revisão minuciosa dos prontuários médicos dos pacientes, dos quais foram extraídas informações clínicas (diagnóstico, tempo pós-TMO, incidência de complicações e patologias associadas ao TMO, como a Doença do Enxerto Contra o Hospedeiro).

\section{Procedimento de coleta de dados}

As entrevistas foram realizadas em um ambiente preservado e gravadas em áudio, mediante o consentimento dos pacientes. O roteiro semi-estruturado previamente estabelecido foi empregado com a necessária flexibilidade, de modo a permitir adaptações quanto à seqüência mais adequada de questões para cada caso. A entrevista foi aplicada individualmente, em situação face-a-face, no decorrer de um único encontro, realizado em sala reservada da instituição hospitalar.

\section{Procedimento de análise dos dados}

A entrevista foi transcrita na íntegra e literalmente. Em sua análise foi utilizada uma abordagem qualitativa, visando identificar o percurso particular de cada paciente na construção do seu cotidiano. Como recurso metodológico para a sistematização dos dados foi utilizada a análise de conteúdo temática (TRIVIÑOS, 1992; MINAYO, 1994).

\section{Aspectos éticos}

A coleta de dados iniciou-se após a sua aprovação no Comitê de Ética em Pesquisa do Hospital das Clínicas da Faculdade de Medicina de Ribeirão Preto-USP (processo $\mathrm{HCRPn}^{\circ} 3560 / 2002$ ). A pesquisa só foi realizada com aqueles que concordaram abertamente em participar do trabalho e assinaram o Termo de Consentimento Livre e Esclarecido formalizando sua anuência.

\section{RESULTADOS}

A análise de conteúdo evidenciou as seguintes categorias temáticas produzidas pelos pacientes entrevistados: (1) Situação ocupacional atual e antes do TMO; (2) Mudanças e dificuldades encontradas no percurso de construção do cotidiano; (3) Limitações decorrentes do TMO; (4) Enfrentamento diante das dificuldades encontradas; (5) Preocupações manifestadas; (6) Planos futuros.

\section{(1) Situação ocupacional atual e antes do TMO}

Ao descreverem como estavam vivendo e quais eram os afazeres e ocupações que mantinham como parte de seu dia-a-dia antes do TMO, a maioria dos sujeitos relatou que tinha uma vida com poucas opções de escolha. Oriundos de famílias pobres, eles necessitaram parar de estudar precocemente, para começarem a trabalhar com o objetivo de ajudar no sustento da casa. Utilizando a maior parte do dia para trabalhar, restava pouco tempo e condições reais de investimento para a construção de atividades sociais sistematizadas, incluindo atividades de lazer, contemplação, autocuidado e descanso. A carência acentuada de recursos econômicos e a preocupação imediata com as condições materiais de sobrevivência eram a tônica de quase todas as entrevistas.

A maioria dos sujeitos que apresentavam maior tempo pós-TMO descreveram sua nova vida apontando as diferenças em relação a que viviam antes do TMO, mostrando que adquiriram uma nova forma de organizar e valorizar seu cotidiano. Já os pacientes que haviam sido transplantados mais recentemente (até um ano pós-TMO) descreveram seu dia-a-dia totalmente preenchido por atividades de autocuidado, permanecendo atentos e concentrados com as freqüentes orientações médicas, como por exemplo, a introdução de uma nova medicação, a retirada de outros remédios, os ajustes nas doses, os horários rígidos para beber água filtrada e os cuidados rigorosos com a alimentação pré-determinada.

\begin{abstract}
"Eu levanto cedo, seis horas, vou lá pro ambulatório, faço os exames, volto, às vezes quando eu chego muito cedo eu deito de novo e durmo, depois eu almoço. Esse é meu dia”. (K, 32 anos, casada, sexo feminino, anemia aplástica grave, balconista, três meses pós-TMO)
\end{abstract}

\section{(2) Mudanças e dificuldades encontradas no percurso de construção do cotidiano}

Os pacientes recém-transplantados relataram que a maior dificuldade encontrada para a retomada da vida era a necessidade iminente de cuidar da saúde. Precisavam ficar 
atentos aos cuidados do corpo, o que implicava em obedecer obsessivamente as prescrições médicas, internalizadas como regras rígidas de conduta. Isso os impedia muitas vezes de construir um espaço para se ocuparem com outras tarefas ou interesses pessoais. Muitos dos pacientes confessaram que reagiam agressivamente a essas imposições, protestando e até mesmo se negando a realizar todas as atividades de autocuidado prescritas. Precisavam, assim, de pessoas sempre por perto para ajudálos, mesmo em atividades aparentemente simples e triviais. Por exemplo, às vezes recusavam-se a tomar a quantidade diária de água necessária ou a passar filtro solar duas vezes ao dia. Esse comportamento rebelde era freqüentemente motivo de discussões ("brigas") com a equipe. Outros pacientes reagiam passivamente frente a essas necessidades, porém revelaram que não conseguiam aprender as novas atividades, necessitando da supervisão de um cuidador familiar, ou seja, mantendo também um padrão dependente da ajuda de outras pessoas, tanto familiares como profissionais da equipe.

\begin{abstract}
"Ai, foi difícil, quer dizer, tá sendo... Acostumar com as transformações, que muda sua aparência, sua cabeça, os pensamentos, até por dentro também, estômago, intestino, a boca, demora para começar a sentir os gostos das comidas novamente... Muda tudo e demora pra voltar, mas até você entender, ter esperança que você vai voltar a ser o que era, ou sei lá, diferente, demora um pouco e você fica privada de muitas coisas, né, tudo que vocêfazia antes e hoje você não pode fazer, então fica difícil..." (F, 25 anos, sexo feminino, portadora de leucemia mielóide crônica, lavradora, solteira, quatro meses pós-TMO)
\end{abstract}

Já os pacientes que estão mais distantes do TMO oferecem outras possibilidades de atribuição de significados a esse tempo depois do transplante. Observa-se que muitos conseguiam perceber e descrever que as mudanças na vida pós-TMO foram necessárias não somente pelas limitações e pela disciplina espartana imposta pelo tratamento, mas como uma forma de construir um novo cotidiano mais saudável, abrindo espaços para a construção de algo próprio, com um significado particular, que permitisse a subjetivação da enfermidade que quase consumiu suas vidas. De fato, muitos pacientes apontaram como uma dificuldade que enfrentavam justamente a possibilidade de construir algo significativo na transição e adaptação para o seu novo contexto de vida. Alguns, talvez por não se permitirem viver esses momentos reflexivos evocados pelo próprio sofrimento, acabam planejando e desejando reconstruir o cotidiano exatamente como era antes do TMO, sem vislumbrarem a potencialidade de transformação e de construir novas possibilidades.
As mudanças mais subjetivas, ocorridas no estilo de vida, também foram encontradas, como se esses sobreviventes sentissem que carregam consigo o signo da vitória conquistada após uma árdua batalha. Esse trunfo, representado pela conquista da possibilidade de uma nova vida, favorece a revisão de conceitos e valores que se tinha anteriormente, deslanchando um processo de completa ressignificação do existir.

"Eu acho que antes do transplante eu levava uma vida muito, assim sabe, é... sem objetivo. Ah, tudo tava bom. Agora não, agora eu acho que estou mais objetiva e posso pensar melhor na vida, porque pequenas coisas que você não daria valor antes, hoje eu já dou, que não teve muita importância e agora já tem”. (K, 38 anos, sexo feminino, portadora de leucemia mielóide crônica, microempresária, casada, três anos pós-TMO)

\section{(3) Limitações decorrentes do TMO}

As limitações vivenciadas no pós-TMO representam um desafio tanto para o paciente quanto para a equipe de saúde. Assim que o paciente tem alta da enfermaria, juntamente com seu cuidador familiar, recebe da equipe uma lista de recomendações a serem seguidas rigorosamente, tais como: usar máscara diariamente, não mexer em terra ou permanecer em locais sujos, não dirigir, não comer comidas cruas, só tomar água fervida, não passar roupa, não freqüentar locais em que haja aglomerações como igrejas, shopping, shows e festas comunitárias, não expor-se ao sol, não manter relações sexuais, dentre outras prescrições médicas que acabam limitando fortemente a obtenção de satisfação e bem-estar pessoal, além de favorecerem situações que podem gerar constrangimento, desconforto ou privação.

$\mathrm{Na}$ medida em que o paciente vai se recuperando e, paulatinamente, melhora sua condição clínica e sua resposta imunológica, essas limitações tendem a diminuir progressivamente, perdurando, entretanto, alguns impedimentos, tais como a restrição à exposição ao sol.

Observou-se que a maioria dos pacientes vai negociando diariamente com a equipe liberações graduais dessas limitações, como um maneira de retomar o sentimento de domínio sobre a própria vida, que é em larga medida perdido com a doença e o tratamento invasivo. Esta parece também ser uma estratégia de enfrentamento que encontram para reconstruir seu cotidiano, confrontando seus desejos e anseios. Após um tempo de luta acirrada contra a doença e os efeitos adversos do tratamento, podem finalmente desfrutar de um tempo de relativa paz e encarar o desafio de começar de novo a alimentar sonhos e planos futuros, 
vendo-se nesse momento com a responsabilidade de projetar uma nova vida.

Nota-se, contudo, que existem pacientes que, mesmo estando mais distanciados temporalmente do TMO, parecem não conseguir superar as vivências traumáticas enfrentadas. O tempo de luta é sucedido por um tempo de profundo recolhimento. Esses pacientes encontram dificuldades de conviverem com uma nova temporalidade, agora isenta dos reveses da doença e dos percalços dolorosos do tratamento. Parecem ter maior dificuldade de superar a experiência traumática, vivendo as restrições impostas pelo tratamento como se estivessem acabado de ser transplantados, isto é, como se as limitações os impedissem objetivamente de reconstruir um cotidiano mais saudável.

"Eu gosto muito de ir pra igreja, na missa. Mas às vezes a gente tem dificuldade, porque tem dia que tá frio. Não tem como ir. É longe... Sair de casa eu já não saio mais. (...) $O$ sol quente, a dificuldade, poeira... (...) Eu não posso lavar roupa... Os serviços de casa a gente já faz, mas com dificuldade". (I, 52 anos, sexo feminino, portadora de leucemia mielóide crônica, do lar, casada, quatro anos pósTMO)

\section{(4) Modos de enfrentamento diante das dificuldades encontradas}

A maioria dos pacientes referiu que a forma que mais utilizaram para enfrentar as dificuldades foi tentando se engajar em algumas atividades, sendo no começo um envolvimento ocasional, mas que ao perceberem a efetividade acabaram se arriscando e se permitindo experimentar outras atividades, que antes não eram valorizadas, mas subestimadas ou sufocadas pela rotina de trabalho.

\begin{abstract}
"É como eu te disse, quando eu fico muito em casa, eu saio pra andar de bicicleta, vou para casa da mãe que não é nada, mais é uns 20 minutos de bicicleta, então eu vou pra lá, fico um pouco, viro de volta, né, e é assim a coisa... Porque ficar dentro de casa não dá!’ (J, 35 anos, sexo masculino, leucemia mielóide crônica, casado, mecânico, nove meses pós-TMO)
\end{abstract}

\section{(5) Preocupações manifestadas}

Os pacientes que estão há menos tempo transplantados expressaram mais claramente a preocupação com a possibilidade de recidiva. Vivenciam esse medo da doença voltar como se estivem lutando diariamente contra um fantasma - uma ameaça contínua e constante, porém intangível, que freqüentemente se manifesta em forma de pavor ou de um sentimento difuso de ansiedade. Essas preocupações muitas vezes são associadas com a necessidade emergencial de se manterem sempre alertas e atentos para não negligenciarem as atividades de autocuidado. Essa necessidade intensa de atenção exige a adoção de uma postura hiper-vigilante, que para ser mantida consome um montante apreciável de energia livre. Muitos pacientes parecem ter uma clara consciência do estresse acarretado - ou seja, há um custo elevado para estar sempre se auto-monitorando e vigiando.

"Olha, é uma preocupação que eu acho que entre dez. transplantados, só um que não tem essa preocupação, porque os outros nove têm, que é da doença voltar. Tenho muito medo de eu ter uma recaída, de ter a infelicidade da minha doença voltar..." (F, 25 anos, sexo feminino, portadora de anemia aplástica grave, casada, manicure, 10 meses pós-TMO).

Já os pacientes que estão há mais tempo transplantados referem preocupações bem mais palpáveis e concretas, tais como a subsistência dos filhos, a autonomia financeira e o anseio de encontrarem uma profissão com a qual se identifiquem.

\section{(6) Planos futuros}

Os pacientes recém-transplantados relataram ter dificuldades de pensar em planos futuros, de planejar suas vidas a longo prazo. Alegam que conseguem apenas se concentrar, em primeiro lugar, no desejo de não precisar ter retornos tão freqüentes ao hospital, de poder permanecer por mais tempo na casa do GATMO, atribuindo a ela um significado de transição para o mundo externo e o retorno ao lar. Depois, programavam ansiosamente a volta para casa, seguida por retornos cada vez mais espaçados ao hospital, e só então poderiam conseguir pensar em planos de vida e não apenas relativos ao tratamento. Assim, permaneciam mais cautelosos com relação ao futuro, envolto em incerteza.

“Não, eu acho que é igual aquela música: 'O futuro é Deus
quem manda'... Eu tô mais preocupada com o presente, o
futuro eu não quero pensar muito não, porque quando você
menos espera já tá virado de ponta-cabeça. Eu não penso
no futuro". (L, 32 anos, sexo feminino, portadora de anemia
aplástica grave, manicure, solteira, quatro meses pós-TMO).

Em contrapartida, os pacientes há mais tempo transplantados relataram vários planos que, uma vez concretizados, implicariam em significativas mudanças em suas vidas, tais como: voltar a estudar, ampliar os 
conhecimentos dentro de sua profissão, construir uma nova casa e casar.

\section{DISCUSSÃO}

Os pacientes que passaram pela experiência radical do transplante de medula óssea, como pôde ser visto e fartamente documentado nos resultados discutidos no presente estudo, apresentam uma necessidade imperiosa de construir seu cotidiano. A doença grave, potencialmente fatal, seguida de um tratamento por vezes tão ou mais agressivo, baseado em um procedimento altamente invasivo como o TMO, interrompe a linha de continuidade da existência, abrindo uma fenda profunda no sentimento de identidade pessoal e profissional. Mas também pode-se imaginar que é justamente porque há uma ruptura brutal do cotidiano que se pode criar a possibilidade de uma nova construção, abrindo brechas para vencer as sérias dificuldades de reinserção social que enfrentam no seu retorno gradual à vida.

Benetton (1999) descreve a história dessas pessoas que, por algum motivo, têm suas histórias marcadas por ausências ou desorganizações das atividades que sustentam o cotidiano, como indivíduos que permanecem no tempo à espera: da hora de tomar o remédio, de ir ao retorno médico, de submeter-se aos cuidados de enfermagem. São pessoas reguladas pelo compasso de espera: a hora de tomar banho, a hora de tomar água, de fazer as refeições, não existindo um sujeito que vive este tempo de forma ativa, mas um tempo que antecede o sujeito e anuncia atividade: de sobrevivência e cuidados clínicos, incorporados ao seu dia-a-dia como parte inexorável de uma rotina alienante e inflexível, que é oferecida como uma benesse, ou antes, uma obrigação, para quem "ganhou a vida novamente".

Para Benetton (1999), a exclusão é resultante de uma diferença simbolicamente marcada pela falta, que fatalmente marginaliza o indivíduo desgarrado da rede social pela repercussão que essa falta acarreta em qualquer tipo de produção, interferindo na construção de cotidianos.

As necessidades subjetivas desses pacientes, antes de serem identificadas e inseridas socialmente no circuito das trocas simbólicas que se estabelecem na relação com o outro mediante o exercício de alguma atividade profissional, assumem uma dimensão empobrecida, restringindo-se a conseguir reproduzir um protocolo mínimo de exigências máximas para a manutenção do corpo biológico. Como auxiliá-los a superar essa perspectiva que esmaga sua subjetividade e estreita seus horizontes existenciais? Este é o desafio dos profissionais que se ocupam dos cuidados com os aspectos da saúde mental desses pacientes.

Em primeiro lugar, é necessário garantir a humanização do tratamento. Para tanto, é preciso que a equipe multiprofissional compreenda profundamente a necessidade de abordar o paciente de forma integral, reconhecendo-o em suas dimensões biopsicossociais. Só assim será possível ajudá-lo a construir um lugar singular a partir de seus próprios recursos, tempo e ritmo, no qual o seu jeito próprio e o seu modo de existir possam acontecer e tornar sua produção particular e única. Dessa matéria-prima original é que o paciente necessita se apropriar para reconstruir seu cotidiano. Como geralmente ocorre com qualquer pessoa que atravessa uma catástrofe, é necessário, passado o cataclisma do TMO, primeiramente erguer-se sobre os escombros, juntar os cacos remanescentes para, posteriormente, tentar reconstruir o cotidiano a partir dos destroços e das partes vivas que sobreviveram à crise.

A Terapia Ocupacional, como nota Takatori (2001), é uma profissão que propõe oferecer ao paciente espaços de saúde, onde o fazer particular do sujeito possa acontecer, a princípio, na relação entre terapeuta ocupacional, paciente e atividades, ampliando-se paulatinamente a outras relações e espaços sociais, contribuindo assim para a inserção social que acontece ao longo de um continuum que constitui - e que é também onde se dá - o cotidiano.

\section{CONCLUSÃO}

O tempo pós-TMO está diretamente relacionado com a construção do cotidiano dos indivíduos sobreviventes do transplante. Esse fenômeno pode ser atribuído a uma esperada melhora gradual da condição orgânica do paciente e à redução das limitações decorrentes do próprio tratamento (impossibilidade de exercer atividades que envolvam esforços físicos, uso intensivo de medicações, retornos ambulatoriais frequientes, possibilidade de recaída da doença, dependência dos familiares, dentre outras).

Os dados sistematizados mostram dificuldades, mas também indicadores que sugerem possibilidades de readaptação psicossocial no pós-TMO. Esse resultado é importante na medida em que cada vez mais o transplante de medula óssea tem se firmado como importante opção terapêutica para diversas enfermidades. 
MASTROPIETRO, A. P. et al. Sobreviventes do transplante de medula. Rev. Ter. Ocup. Univ. São Paulo, v. 17, n. 2, p. 64-71, maio/ago., 2006.

MASTROPIETRO, A. P.; SANTOS, M. A.; OLIVEIRA, E. A. Bone marrow transplantation survivors: reconstruction of daily living. Rev. Ter. Ocup. Univ. São Paulo, v. 17, n. 2, p. 64-71, maio/ago., 2006.

\begin{abstract}
Bone Marrow Transplantation (BMT) is a highly complex procedure whose development over the last few decades has allowed the treatment of diseases that used to be invariably fatal. The transplant consists of several stressful phase for the patient consisting of three main times: pre-BMT, BMT proper, and post-BMT phase. The last phase is marked by a series of restrictions for the patients, whose daily life routine undergoes a total change. The main objective of the present study was to assess the (re)construction of daily living in patients submitted to BMT. The sample consisted of 24 patients in the post-BMT phase. The instrument which was used for data collection was the Post-BMT Recovery Interview (PBMT-RI). The interview was taped, transcribed verbatim in full and then analyzed using a qualitative approach, i.e. thematic content analysis. The results indicated that the time post-BMT is strongly associated with the reconstruction of daily living in survivors of BMT. This phenomenon may be attributed to an expected gradual improvement in patient organic condition and reduction of the limitations due to treatment itself (impossibility to carry out activities involving physical effort, use of medications, frequent ambulatory return visits, and possibility of disease recurrence, among others). These indicators of post-BMT readaptation are an important result since transplant is being definitely considered to be an important therapeutic option for different diseases.
\end{abstract}

KEY WORDS: Occupational therapy. Bone marrow transplantation/adaptation psychological. Bone marrow transplantation/rehabilitation. Bone marrow transplantation/psychology. Social support. Rehabilitation.

\title{
REFERÊNCIAS
}

ANDRYKOWSKI, M. A. Psychiatric and psychological aspects of bone marrow transplantation. Psychosomatics, v. 35, n. 1, p. 13-24, 1994.

BENETTON, M. J. Trilhas associativas: ampliando recursos na clínica da terapia ocupacional. São Paulo: Diagrama \& Texto/ CETO - Centro de Estudos de Terapia Ocupacional, 1999.

FERRARI, S. M. L.; TEDESCO, S.; BENETTON, M. J. Laboratório de análises de atividades: cotidiano e terapia ocupacional. Manuscrito do CETO - Centro de Estudos de Terapia Ocupacional, 2002.

HELLER, A. O cotidiano e a história. 6a ed. São Paulo: Paz e Terra, 2000.

MINAYO, M. C. S. O desafio do conhecimento: pesquisa qualitativa em saúde. São Paulo: Hucitec/Abrasco, 1994.

PATON, E. J. A.; COUTINHO, M. A.; VOLTARELLI, J. C.
Diagnóstico e tratamento de complicações agudas do transplante de células progenitoras hematopoéticas. Medicina, Ribeirão Preto, v. 33, n. 3, p. 264-277, 2000.

TAKATORI, M. A terapia ocupacional no processo de reabilitação: construção de cotidiano. Mundo da Saúde, São Paulo, v. 25 , n. 4, p. 371-383, 2001.

TAKATORI, M. O brincar no cotidiano da criança com deficiência física: reflexões sobre a clínica da terapia ocupacional. São Paulo: Atheneu, 2003.

TRIVIÑOS, A. N. S. Introdução à pesquisa em ciências sociais: a pesquisa qualitativa em educação. São Paulo: Atlas, 1992.

VOLTARELli, J. C.; STRACIERI, A. B. P. L. Aspectos imunológicos dos transplantes de células tronco hematopoiéticas. Medicina, Ribeirão Preto, v. 33, p. 443-462, 2000.

Recebido para publicação: Março/2006

Aceito para publicação: Abril/2006 